\title{
Kegagalan Strategi Transnational Advocacy Network dalam Menentang Pengesahan Qanun Jinayat di Aceh
}

\author{
Jessica Aulia, Nurul Isnaeni, dan R. Maisa Yudono \\ Universitas Indonesia
}

\begin{abstract}
ABSTRAK
Penelitian ini membingkai kegagalan advokasi terhadap Qanun Jinayat di Aceh sebagai permasalahan strategi perjuangan. Dalam penelitian ini, penulis menggabungkan penelusuran literatur dan penelitian lapangan di Banda Aceh. Sebagai bagian dari debat besar antara paham universalis dan partikularis terkait isu-isu Hak Asasi Manusia (HAM), NGO-NGO setempat beraliansi dengan NGO-NGO internasional dalam sebuah jejaring aktivis yang oleh Keck dan Sikkink (1998) dirujuk sebagai Transnational Advocacy Network (TAN). Upaya advokasi telah dilakukan melalui berbagai pendekatan sesuai dengan empat tipe strategi yang diungkapkan oleh Keck dan Sikkink (1998). Meski demikian, strategi-strategi tersebut kurang efektif dalam kasus ini karena berbagai hambatan seperti kompleksitas hukum Indonesia, perbedaan tujuan akhir antar elemen-elemen TAN, serta ketiadaan tokoh representatif dalam isu ini. Akibatnya, dapat disimpulkan bahwa meskipun pola advokasi transnasional telah nampak di Aceh, keberadaan jejaring transnasional tersebut belum berhasil mengadvokasikan tidak disahkannya Qanun Jinayat.
\end{abstract}

Kata Kunci: Aceh, hak asasi manusia, Qanun Jinayat, transnational advocacy network

This research paper frames the failure of contention against Islamic Criminal Law (Qanun Jinayat) in Aceh as a strategic problem. In this research, the authors combine literature research and field observation in Banda Aceh. Amidst the debate between the universalist and particularist point of view regarding human right issues, local NGOs fighting against Qanun Jinay at have linked themselves with INGOs in a network of activists which Keck and Sikkink (1998) refers to as Transnational Advocacy Network (TAN). It has undertaken multiple approaches aligned to the four types of strategies as underlined by Keck and Sikkink (1998). However, such strategies are ineffective due to multiple features of the advocacy such as complexity of Indonesian law, difference in final objective of the elements of TAN, and lack of strong representative figure as the front of the advocacy. In all, it can be concluded that although the pattern of transnational advocacy has emerged in Aceh, presence of such transnational network has not successfully advocated against the legalization of Qanun Jinayat.

Keywords: Aceh, human rights, Qanun Jinayat, transnational advocacy network 


\section{Pendahuluan}

Semenjak berakhirnya Perang Dingin, ilmu Hubungan Internasional semakin diperkaya dengan munculnya kajian-kajian transnasionalisme. Kajian transnasionalisme dalam ilmu Hubungan Internasional mempelajari interaksi berkelanjutan yang melintasi batas negara dengan sekurang-kurangnya salah satu aktornya merupakan agen non-negara, atau aktor yang tidak bertindak atas nama pemerintah negara, atau organisasi antarpemerintah (Risse 1995, 3). Dengan demikian, ilmu Hubungan Internasional tidak lagi hanya terpusat pada pembahasan aktor-aktor negara saja melainkan juga mencakup peran aktor-aktor non-negara dalam perpolitikan global.

Salah satu konsep sentral dalam kajian transnasional adalah jejaring advokasi transnasional / Transnational Advocacy Network (TAN). Menurut Keck dan Sikkink (1999, 89-91), TAN merupakan jejaring aktivis yang terikat oleh nilai-nilai dan tujuan bersama, yang disosialisasikan melalui pertukaran informasi yang berkesinambungan. Jejaring aktivis tersebut memperjuangkan emansipasi dan memberdayakan kelompok-kelompok yang termarjinalkan. Umumnya, perjuangan tersebut ditujukan kepada pemerintah sebagai aktor pembuat kebijakan di sebuah negara.

Untuk mencapai kepentingan tersebut, kelompok aktivis setempatbaik yang tergabung dalam NGO nasional maupun NGO lokalterkadang berkoalisi dengan mitra-mitranya di luar negeri, dengan harapan kemitraan tersebut memunculkan tekanan internasional pada sebuah isu. Strategi sedemikian rupa disebut oleh Keck dan Sikkink (1999) sebagai pola bumerang. Pada beberapa kasus, pola bumerang berhasil mencapai tujuan, yaitu perubahan kebijakan yang sebelumnya bersifat memarjinalkan (Sperling et al. 2001; Krain 2012; Noakes 2012). Meski demikian, di beberapa kasus yang lain, kemunculan TAN tidaklah cukup untuk menekan aktor pemerintah yang menjadi target advokasi untuk mengubah kebijakannya (Nelaeva 2010; Waworuntu dalam Soetjipto 2015).

Tulisan ini membahas dan menganalisis salah satu kasus kegagalan advokasi TAN, yaitu dalam advokasi menentang disahkannya Qanun No. 6 Tahun 2014 tentang Hukum Jinayat ("Qanun Jinayat") di Nanggroe Aceh Darussalam. Dalam kasus tersebut, TAN terbentuk karena kelompok-kelompok masyarakat sipil di Aceh seperti Solidaritas Perempuan Bungeong Jeumpa Aceh (SP Aceh), Koalisi NGO HAM Aceh, dan Kontras Aceh tidak mendapatkan akses terbuka terhadap proses penyusunan Qanun Jinayat. Untuk menggalang kekuatan, NGO-NGO lokal tersebut, dengan dukungan NGO-NGO 
nasional yang berjuang di tingkat pusat seperti Institute for Criminal Justice Reform (ICJR), berjejaring dengan NGO-NGO internasional (INGO) seperti Amnesty International dan Human Rights Watch. Di sini, pola bumerang sudah terlihat dengan jelas dengan terbentuknya dengan terbentuknya jejaring aktivis / TAN tersebut.

Berbagai upaya advokasi telah dilakukan oleh TAN mulai pada tingkat lokal di Aceh, tingkat nasional di Jakarta, maupun dalam skala global. Namun demikian, advokasi TAN di Aceh berakhir dengan kegagalan. Pada tanggal 22 Oktober 2014, Pemerintah Provinsi Nanggroe Aceh Darussalam (Pemprov Aceh) menetapkan Qanun Jinayat sebagai instrumen hukum yang sah, untuk selanjutnya diberlakukan mulai 23 Oktober 2015 (Linggasari 2015).

\section{Perkembangan Qanun Jinayat di Aceh}

Berdasarkan sensus Badan Pusat Statistik (2010), penduduk Aceh adalah 4.490.410 jiwa, dengan mayoritas penduduknya $(98,5 \%)$ beragama Islam (Dirjen Kependudukan dan Pencatatan Sipil 2015). Berdasarkan UU No. 18 tahun 2001 tentang Otonomi Khusus bagi Provinsi Daerah Istimewa Aceh sebagai Provinsi Nanggroe Aceh Darussalam, Pemerintah Provinsi Aceh berhak mengeluarkan qanun yang memiliki kekuatan hukum setara dengan peraturan daerah (Perda) (UU No. 18/2001, Pasal 1(8)). Penerapan Qanun Jinayat di Aceh tidak terlepas dari pentingnya Syariat Islam dalam kehidupan bermasyarakat di Aceh. Sejarah penerapan Syariat Islam di Aceh dapat ditelusuri dari Kerajaan Aceh Darussalam. Aceh yang sering disebut dengan Serambi Mekkah ini telah menerapkan Syariat Islam jauh sebelum kemerdekaan Republik Indonesia. Menurut para ahli sejarah, Kerajaan Aceh didirikan oleh Sultan Ali Mughayatsyah (1516-1530) telah mengimplementasikan Syariat Islam sebagai dasar kerajaan (Aunie 2001).

Pada masa Orde Lama, Presiden Soekarno pernah berjanji kepada Aceh akan memberikan kewenangan untuk mengatur beberapa hal terkait daerahnya sendiri, termasuk di dalamnya mengenai regulasi daerah yang berbasis Islam (Rasyid 2001). Janji tersebut ditetapkan secara simbolis melalui diberikannya status daerah istimewa untuk Provinsi Aceh. Namun kemudian, kewenangan Aceh untuk mengatur daerahnya sendiri tidak juga terwujud. Hal tersebut merupakan salah satu dari penyebab munculnya Gerakan Aceh Merdeka, di bawah pimpinan salah satunya Daud Beureueh (Rasyid 2001). Akhirnya, pada masa pemerintahan Orde Baru, di bawah kepemimpinan Presiden Soeharto, wacana keistimewaan khusus bagi Aceh 
kembali disuarakan. Pada tahun 1999, Aceh akhirnya mendapatkan keistimewaan dari Presiden Indonesia yang dirumuskan dalam Undang-Undang No. 44/1999 mengenai Keistimewaan Aceh. Terdapat empat perkara yang diatur dalam Undang-Undang ini, diantaranya penyelenggaraan kehidupan beragama, penyelenggaraan kehidupan adat, penyelenggaraan pendidikan, serta peran ulama dalam penetapan kebijakan daerah. Selanjutnya, berdasarkan Undang-undang No. 18/2001 tentang Otonomi Khusus bagi Provinsi Daerah Istimewa Aceh sebagai Provinsi Nanggroe Aceh Darussalam dan diperkuat Undang-undang No. 11/2006 tentang Pemerintahan Aceh (UUPA), Pemprov Aceh memiliki kekuatan hukum untuk membentuk sendiri Perda yang khusus untuk Aceh disebut sebagai qanun.

Cikal bakal pembentukan Qanun Jinayat dimulai dengan program legislasi pada tingkat provinsi yang diinisiasi oleh DPRA. Pada tanggal 6 November 2008, Pemprov Aceh menggunakan hak usul inisiatif (prakarsa) untuk mengajukan Rancangan Qanun (raqan) untuk dibahas pada tingkat legislatif DPRA dengan melampirkan naskah kajian akademik. Selanjutnya, Wakil Gubernur Aceh Muhammad Nazar sebagai perwakilan eksekutif secara resmi mengajukan Rancangan Qanun (raqan) di hadapan masa persidangan Dewan Perwakilan Rakyat Aceh keempat tahun 2009 (Amsori dan Jailani 2017, 234-236). Sejalan dengan pembahasan raqan di DPRA, sosialisasi dan konsultasi publik juga mulai dijalankan dengan melibatkan masyarakat umum. Konsultasi publik sudah dilakukan melalui proses dengar pendapat (public hearing), dengan memberikan kesempatan mengeluarkan pendapat bagi kelompok-kelompok masyarakat. Elemen-elemen masyarakat yang terlibat dalam dengar pendapat ini antara lain perwakilan dari para ulama yang tergabung dalam Majelis Permusyawaratan Ulama (MPU), akademisi, NGO, pengacara, OKP dan organisasi kemahasiswaan (Amsori dan Jailani 2017, 237).

Setelah disetujui bersama oleh pihak eksekutif dan legislatif, Rancangan Qanun Jinayat selanjutnya disampaikan oleh pimpinan DPRA kepada Gubernur Aceh yang saat itu dijabat oleh Irwandi Yusuf. Pada tanggal 22 Juni 2009, pihak eksekutif menyatakan tidak akan menandatangani raqan dikarenakan masih belum menyetujui klausul pengenaan hukuman rajam dan meminta penundaan pengesahan raqan. Meski demikian, raqan akhirnya disahkan oleh DPRA tanpa tanda tangan Gubernur Aceh pada tanggal 14 September 2009 (The Wahid Institute 2009). Setelah melalui berbagai proses politik, akhirnya Qanun Jinayat baru ditetapkan pada tanggal 22 Oktober 2014. 


\section{Perjuangan Transnational Advocacy Network sebagai Kontestasi Partikularitas dan Universalitas HAM}

Pertentangan gagasan antara Pemprov Aceh dan jejaring masyarakat sipil di Aceh dapat dilihat sebagai manifestasi dari debat prinsip partikularitas dan universalitas dalam HAM. Dalam kasus Qanun Jinayat di Aceh, pertentangan tersebut dapat dilihat pada posisi dasar Pemprov Aceh dan posisi jejaring masyarakat sipil di Aceh. Di satu sisi Pemprov Aceh memegang prinsip partikularitas yaitu menerapkan Syariat Islam sebagai standar pemenuhan HAM, sedangkan di sisi lain jejaring masyarakat sipil mengedepankan pandangan universalitas dengan mengacu kepada prinsip-prinsip universal HAM.

Di satu sisi, pendekatan partikularisme dalam HAM mengandung makna bahwa tiap-tiap manusia di dunia merupakan individu yang unik, masing-masing tidak terlepas dari konteks sosial budaya yang dialaminya. Jadi, kebutuhan tiap-tiap individu harus dipertimbangkan, termasuk dalam penyusunan sebuah produk hukum (Douzinas 2002, 384-402). Perbedaan tersebut tidak terlepas dari perbedaan nuansa ("nuances") yang terbentuk dari latar belakang identitas dan budaya tiap-tiap individu. Dengan demikian, prinsip partikularisme menolak penyamarataan standar tunggal bagi pemenuhan HAM umat manusia. Partikularisme menekankan pentingnya memahami dan menghormati keragaman konteks sosial budaya pada berbagaikomunitasmasyarakatyang adadidunia.Pemaksaanstandar tunggal pemenuhan HAM di seluruh dunia justru dipandang sebagai sebuah bentuk pelanggaran HAM.

Di sisi lain, pendekatan universalisme dalam HAM memandang bahwa hak asasi manusia merujuk kepada hak-hak yang melekat pada seorang individu dikarenakan martabat alamiah individu tersebut sebagai manusia (Donnelly 2003, 1-10). Hak-hak tersebut dapat berupa hak sipil-politik maupun hak ekonomi-sosial yang keberadaannya bersifat mutlak. Prinsip kemutlakan berarti hak-hak tersebut tidak dapat diberikan dan tidak dapat dicabut oleh pihak manapun, termasuk pemerintah di sebuah negara. Melalui Deklarasi Universal Hak Asasi Manusia (DUHAM), pemerintah-pemerintah negara-negara di dunia menyepakati hak-hak dimaksud. Pendekatan universalisme memandang adanya standar tunggal pemenuhan HAM yang wajib dilakukan oleh pemerintah suatu negara.

\section{Strategi Politik Informasi}

Strategi politik informasi merupakan kemampuan TAN untuk menghasilkan informasi-informasi yang akurat dan dapat dipertanggung- 
jawabkan (Keck dan Sikkink, 1999: 95-96). Informasi tersebut terkadang tidak mudah untuk didapatkan namun sifatnya sangat krusial dalam mempengaruhi diskursus yang sedang berkembang. Salah satu kunci dari strategi ini adalah bagaimana menyusun laporan secara komprehensif serta mudah dipahami. Proses pengumpulan data lapangan dilakukan oleh seluruh elemen TAN. Meski demikian, pada umumnya elemen NGO internasional dalam TAN cenderung untuk menggerakkan kekuatan jaringan NGO setempat yang mempunyai cabang hingga ke akar rumput (Keck dan Sikkink, 1999: 96). Keberadaan jejaring TAN pada tingkatan akar rumput mengakibatkan TAN dapat mengumpulkan informasi-informasi yang terkadang bersifat sensitif, termasuk di antaranya pengalaman pribadi para penyintas. Pola tersebut juga terjadi pada advokasi TAN di Aceh.

Meski demikian, strategi ini menemui hambatan yang cukup besar. SP Aceh menyebutkan bahwa sosialisasi dari Pemprov Aceh mengenai Qanun Jinayat kepada masyarakat Aceh sangatlah minim. Berdasarkan pernyataan di atas, kesadaran masyarakat awam mengenai Qanun Jinayat sangat terbatas. Maka dari itu, SP Aceh harus mengambil peran ganda, yaitu sebagai edukator mengenai Qanun Jinayat itu sendiri dan kemudian baru membawa pesanpesan advokasi. Hal tersebut tentunya menjadi beban bagi NGO setempat karena faktor keterbatasan tenaga dan sumber daya. Padahal, tanggung jawab sosialisasi mengenai produk perundangundangan sejatinya terletak pada Pemerintah Provinsi Aceh.

\section{Strategi Politik Simbolis}

Strategi politik simbolis merupakan kemampuan untuk menerapkan simbol, agar lebih mudah dipahami oleh targetnya (Keck dan Sikkink 1999: 96-97). Simbol-simbol yang diangkat bisa berbentuk tindakan ataupun tokoh tertentu, yang diangkat sebagai representatif dari keseluruhan perlawanan yang dilakukan oleh sebuah. Dengan mempergunakan simbol-simbol, masyarakat umum dapat dengan mudah mengasosiasikan kasus yang diangkat dengan tujuan yang ingin dicapai oleh jejaring TAN. Dalam advokasi Qanun Jinayat, hukuman badan (corporal punishment) merupakan simbol utama yang sering diangkat oleh TAN, baik pada tingkat lokal maupun internasional. Awal mula Qanun Jinayat mendapatkan sorotan publik adalah ketika rancangan qanun terdapat klausul uqubat rajam (stoning) bagi pelaku zina. Hukuman tersebut dipandangtidak lazim dan memiliki nilai kejut (shock value) yang tinggi. Maka dari itu, diangkat sebagai simbol. Qanun Jinayat diidentikkan dengan hukuman rajam. 
Setelah rancangan qanun tersebut tidak ditandatangani oleh Gubernur Aceh saat itu yaitu Irwandi Yusuf, simbol yang diangkat sebagai representatif Qanun Jinayat adalah hukuman cambuk. Narasi-narasi yang dikembangkan oleh TAN di Aceh, baik elemen setempat maupun elemen NGO internasional berpusat pada simbol tersebut. Sebagai contoh, Amnesty International selalu membahas mengenai hukuman cambuk dalam laporan tahunan "The State of The World's Human Rights" sejak tahun 2008 (Amnesty International 2008).

Meski demikian, simbol-simbol yang diangkat merupakan peristiwaperistiwa tertentu semata. Hal tersebut cukup disayangkan mengingat simbol-simbol politik yang berbentuk kasus dan peristiwa semata kurang dapat menjadi faktor penarik terhadap rakyat Aceh apabila dibandingkan dengan simbol ketokohan. Hingga saat ini, masih belum ada ketokohan yang cukup kuat di Aceh, yang dapat dijadikan sebagai simbol perlawanan. Keberadaan simbol ketokohan, terutama tokoh-tokoh yang memiliki daya pikat yang kuat bagi masyarakat, tentunya dapat menarik perhatian masyarakat awam akah advokasi TAN. Hal ini merupakan salah satu kelemahan utama dalam perlawanan TAN di Aceh.

\section{Strategi Politik Pengaruh}

Strategi politik pengaruh merupakan kemampuan jejaring untuk menggunakan aktor-aktor lain yang memiliki kapabilitas lebih untukmemberikan pengaruh terhadap sebuah situasi (Keck dan Sikkink 1999: 97). Aktor-aktor tersebut dapat berupa aktor supranasional seperti organisasi internasional, aktor negara khususnya negara-negara maju maupun aktor non-negara seperti MNC. Pada esensinya, aktor-aktor tersebut memiliki kekuatan yang lebih besar daripada aktor target perlawanan TAN. Menurut Keck dan Sikkink, aktor-aktor tersebut sekurang-kurangnya harus memiliki kuasa untuk membawa isu ini ke pengawasan internasional (international supervision). Dalam melakukan politik pengaruh, TAN melandaskan perjuangannya pada issue linkage, yaitu bagaimana TAN mampu menghubungkan dua isu atau lebih yang sebelumnya tidak pernah dilakukan. Dengan melakukan issue linkage, ruang gerak perlawanan TAN menjadi semakin luas mengingat proliferasi aktor dalam sebuah isu meningkatkan kekuatan jejaring TAN. Strategi politik pengaruh ini sendiri dapat dibagi menjadi dua, yaitu pengaruh materi dan pengaruh moral.

Pengaruh materi biasanya menghubungkan suatu isu dengan uang atau barang dalam konteks ekonomi. Isu-isu yang diperjuang- 
kan oleh TAN terkadang bukanlah isu yang menarik untuk dibahas. Meski demikian, dengan mengaitkan isu tersebut dengan hal yang lebih penting, terutama aspek keuangan, tekanan yang dilakukan kepada aktor target menjadi lebih nyata. Pada kasus Qanun Jinayat, TAN berhasil melakukan pengaruh materi dengan cara mengaitkan dengan isu HAM dan investasi di Aceh. Dalam narasi-narasi yang dikembangkan oleh TAN di dunia internasional, NGO-NGO internasional baik Human Rights Watch maupun Amnesty International menyerukan kepada negara-negara di dunia agar tidak melakukan investasi di Aceh hingga terjadi reformasi hukum di Aceh.

Meski demikian, strategi politik pengaruh yang dijalankan oleh TAN di Aceh menemui hambatan. Salah satu narasi alternatif yang berkembang di masyarakat Aceh adalah pandanganpadangan negatif mengenai para aktivis di sana. Para aktivis yang memperjuangkan norma universalitas dalam HAM diberi label sebagai perpanjangan tangan dari kekuatan-kekuatan asing yang melawan Islam. Pada intinya, narasi alternatif ini menggambarkan advokasi yang dilakukan oleh aktivis setempat bukan sebagai bagian dari keinginan masyarakat Aceh itu sendiri. Kuatnya narasi alternatif ini merupakan hambatan yang cukup berarti bagi TAN, khususnya elemen-elemen lokal dan nasional, dalam melakukan strategi politik pengaruh. Kunci utama dari strategi politik pengaruh adalah melibatkan aktor-aktor baru yang sebelumnya tidak terlibat dalam sebuah advokasi, dengan melakukan issue linkage. Sayangnya, proliferasi aktor pada kasus ini justru memperburuk citra TAN, khususnya NGO setempat. Sebagai contoh, tertahannya investasi MNC asing di Aceh akibat advokasi TAN di tingkat internasional justru memperkuat dugaan bahwa pihak-pihak tertentu ingin menghambat pembangunan di Nanggroe Aceh Darussalam.

\section{Strategi Politik Akuntabilitas}

Strategi politik akuntabilitas merupakan tindakan-tindakan yang ditempuh oleh TAN agar janji-janji politis yang telah dilakukan oleh para pembuat kebijakan ditepati (Keck dan Sikkink 1999, 9798). Dalam proses politik, pembuat kebijakan, baik di tingkat pusat maupun daerah sering menjanjikan hal-hal tertentu di hadapan konstituennya. Tetapi terkadang kebijakan pemerintah bertolak belakang dengan komitmen politik yang telah diambilnya. TAN dapat melakukan check and balances dengan mengingatkan akan janji-janji tersebut. 
Sehubungan dengan hal tersebut, maka dalam melakukan strategi jenis ini kedekatan dan komunikasi politik dengan pemerintah, baik pemerintah pusat maupun daerah sangat diperlukan. Peran perwakilan komunitas masyarakat sipil di lingkar pengambilan kebijakan menjadi sangat penting untuk dapat secara efektif menempuh strategi ini. Hal ini menjadi lebih penting lagi pada situasi dimana struktur kesempatan politis yang ada kurang memberikan ruang gerak bagi kegiatan-kegiatan aktivisme setempat.

Dari pernyataan di atas dapat dilihat bahwa strategi NGO-NGO khususnya terkait pendekatan dengan Pemprov Aceh cukup beragam, tergantung dengan peran tiap-tiap NGO. Ada NGO yang cenderung bersikap keras dan tegas dalam mengkritisi Pemprov seperti SP Aceh, namun ada juga NGO yang menjalin kemitraan strategis dengan pemerintah Aceh. Pembagian tugas tersebut bertujuan agar perwakilan masyarakat sipil tetap dapat terlibat dalam grand design Syariat Islam di Aceh. Perwakilan inilah yang kemudian berperan untuk memastikan akuntabilitas Pemprov Aceh terhadap janji-janji politisnya, salah satunya mewujudkan penerapan Syariat Islam yang humanis di Aceh.

Sementara itu, di tingkat pusat, strategi politik akuntabilitas banyak dilakukan oleh NGO-NGO internasional terhadap pemerintah Indonesia. NGO-NGO seperti Human Rights Watch dan Amnesty International sering menagih komitmen nyata Indonesia yang sudah meratifikasi CEDAW, CAT, dan perjanjian-perjanjian internasional lainnya. Secara khusus Human Rights Watch seringkali mempergunakan politik akuntabilitas terhadap pemerintah Indonesia. Dalam laporan-laporannya, NGO internasional ini beberapa kali menekan Pemerintah Indonesia untuk mengintervensi Qanun Jinayat.

Namun demikian, kompleksitas isu otonomi daerah di Indonesia terkadang menghambat penerapan strategi politik ini secara efektif. Dalam kasus Qanun Jinayat, advokasi yang dilakukan oleh TAN harus dilakukan pada dua titik, yaitu pada tingkat Pemprov Aceh dan pada pemerintah pusat Indonesia. Sebagai contoh, tidak cukup hanya dengan melakukan advokasi menentang ditetapkannya Qanun Jinayat, TAN juga harus menyerang payung yudikatifnya, antara lain Undang-undang Pemerintahan Aceh. Hal ini dikarenakan salah satu argumentasi dasar Pemprov Aceh, yaitu bahwa kodifikasi Qanun Jinayat hanya sekedar bentuk pelaksanaan dari UUPA.

Imbasnya, strategi politik akuntabilitas harus dilaksanakan den- 
gan mempertimbangkan profil politik para pembuat kebijakan baik pada tingkat lokal dan nasional. Dinamika tersebut mengakibatkan perlunya koordinasi yang sangat erat pada elemen-elemen TAN untuk memastikan bahwa perjuangan dan advokasi yang dilakukan di kedua titik tersebut memiliki sinergi yang kuat. Tentunya posisi TAN cukup diuntungkan dengan keberadaan beberapa NGO yang hadir pada dua titik perlawanan tersebut seperti Serikat Perempuan dan Kontras.

Meski demikian, cukup disayangkan bahwa koordinasi antarakedua titik perjuangan tersebut ini masih belum maksimal. Pada saat penulis melakukan wawancara dengan para narasumber dari NGO, memang disebutkan ada kerja sama antara NGO-NGO tersebut, seperti pengadaan pelatihan maupun pertukaran informasi. Namun demikian, komunikasi yang dilakukan cenderung bersifat sporadis dan bersikap reaktif, bukan sebagai sebuah hal yang berkelanjutan. Akibatnya, strategi politik akuntabilitas tidak dapat dijalankan denganbaik.

\section{Kesimpulan}

Dalam melakukan advokasi, TAN mempergunakan berbagai macam tindakan advokasi mulai dari melakukan kemitraan strategis dengan pemerintah hingga melayangkan surat terbuka untuk menimbulkan rasa malu. Ragam strategi tersebut dapat dibagi menjadi empat tipologi strategi sebagaimana dirumuskan oleh Keck dan Sikkink. Keempat tipologi strategi tersebut yaitu strategi politik informasi (information politics), politik simbolis (symbolic politics), politik pengaruh (leverage politics), dan politik akuntabilitas (accountability politics).

Namun, dampak advokasi TAN Aceh masih sangat kurang, terbukti dengan disahkannya Qanun Jinayat sebagai instrumen hukum yang sah. Berdasarkan temuan penelitian ini, kegagalan tersebut terjadi karena banyaknya hambatan yang muncul dalam advokasi TAN, mengakibatkan kurang efektifnya strategi advokasi yang ditempuh oleh TAN. Penelitian ini mengidentifikasikan empat faktor hambatan yang mengakibatkan kegagalan tersebut. Pertama, minimnya pengetahuan masyarakat umum di Aceh mengenai Qanun Jinayat. Kedua, ketiadaan tokoh utama penggerak advokasi pada isu Qanun Jinayat. Ketiga, label negatif yang dilekatkan kepada para aktivis setempat. Keempat, kompleksitas struktur hukum dan hubungan pusat-daerah. 
Pada kesimpulan, penelitian ini menemukan bahwa pola bumerang sebagaimana digariskan oleh Keck dan Sikkink (1999) dalam sebuah advokasi terhadap sebuah kasus tidak menjamin keberhasilan advokasi tersebut. Meskipun karakter transnasional sebuah perlawanan mungkin dapat membantu mengangkat sebuah isu ke permukaan, terkadang keterlibatan aktor-aktor transnasional tidak menjamin perubahan kebijakan dalam sebuah advokasi. 


\section{Daftar Pustaka}

\section{Buku atau Bab dalam Buku}

Abubakar, Al Yasa', 2006. Syariat Islam di Provinsi Nanggroe Aceh Darussalam: Paradigma, Kebijakan, dan Kegiatan. Banda Aceh: Dinas Syariat Islam Nanggroe Aceh Darussalam.

Afrianty, Dina, 2015. Women and Sharia Law in Northern Indonesia. New York: Routledge.

Ahmad, Mustafa, 1999. Syariat Tanpa Dukungan Adat Susah Berjalan. Banda Aceh: IAIN Ar-Raniry.

Aunie, Luthfie, 2001. "Transformasi Politik dan Ekonomi Kerajaan Islam Aceh (1641-1699)", dalam Pranata Islam di Indonesia: Pergulatan Sosial, Politik, Hukum dan Pendidikan. Jakarta: Logos Wacana Ilmu.

Bosce, Alexandra-Maria, 2011. "Understanding Transnational AdvocacyNetworks: How Political Opportunity Structure Impacts their Emergence", dalam DRC Summer School. Danube: DRC Summer School.

Clark, Anne Marie, 2001. Diplomacy of Conscience: Amnesty International and Changing Human Rights Norms. New Jersey: Princeton University Press.

Dancy, Jonathan, 2006. Ethics without Principles. Oxford: Oxford University Press.

Donnelly, Jack, 2003. Universal Human Rights in Theory and Practice.London: Cornell University Press.

Dunn, Kevin, 2011. "Historical Representations", dalam Audie Klotz dan Deepa Prakash (eds.), Qualitative Methods in International Relations. New York: Palgrave.

Freeman, Michael, 2002. Human Rights: An Interdisciplinary Approach. Cambridge: Polity Press.

Hooker, M. Barry, 2008. Indonesian Syariah: Defining a National School of Islamic Law. Singapore: ISEAS.

Ishay, Michaelin R., 2008. The History of Human Rights: From Ancient Times to the Globalization Era. Berkeley: University of California Press. 
Juned, Tengku, 2011. "Penerapan Sistem dan Asas-asas Peradilan Hukum Adat dalam Penyelesaian Perkara”, dalam Pedoman Adat Aceh: Peradilan dan Hukum Adat. Banda Aceh: LAKA Provinsi NAD.

Kahler, Miles, 2009. "Networked Politics: Agency, Power, and Governance", dalam Miles

Kahler (ed.), Networked Politics: Agency, Power, and Governance. Ithaca: Cornell University Press.

Lipovskaya, Olga, 1997. "Women's Groups in Russia”, dalam Mary Buckley (ed.), Post-Soviet Women: From the Baltic to Central Asia. Cambridge: Cambridge University Press.

Miller, Michelle Ann, 2004. "The Nanggroe Aceh Darussalam Law: A Serious Response to Acehnese Separatism?”, dalam Asian Ethnicity. London: Routledge.

Misran, Tengku, 2012. Pelaksanaan Syariat Islam di Aceh: Analisis Kajian Sosiologi Hukum. Banda Aceh: Ar-Raniry.

Power, Jonathan, 2001. Like Water on Stone: The Story of Amnesty International.Boston: Northeastern University Press.

Risse-Kappen, Thomas, 1995. Bringing Transnational Relations Back In. Cambridge: Cambridge University Press.

Soetjipto, Ani W. (ed), 2015. HAM dan Politik Internasional: Sebuah Pengantar. Jakarta: Yayasan Pustaka Obor Indonesia.

Tilly, Charles dan Tarrow, Sidney, 2015. Contentious Politics. New York: Oxford University Press.

\section{Artikel Jurnal}

Alamdari, Kazem, 2014. "Global Civil-society Movements: What the World Social Forum Can Do to Change the World's Situation", Social Criminal, 2 (2).

Amsori dan Jailani, 2017. "Legalisasi Qanun Jinayat Aceh dalam Sistem Hukum Nasional”, Ar-Raniry International Journal of Islamic Studies, 4 (2).

Bennett, Andrew dan Colin Elman, 2007. "Case Study Methods in the International Relations Subfield”, Comparative Political 
Studies, 40 (2).

Buehler, Michael, 2013. "Subnational Islamization through Secular

Parties: Comparing Sharia Policies in Two Indonesian Provinces", Comparative Politics, 46 (1).

Douz inas, Costas, 2002. "Identity, Recognition, Rights or What Can Hegel Teach Us about Human Rights", Journal of Law and Society, 29 (1).

Fajarni, Suci, 2017. "Pelaksanaan Siyasah Syariah di Aceh”. Jurnal Sosiologi Agama, 9 (1).

Finnemore, Martha dan Kathryn Sikkink, 1998. "International Norm Dynamics and Political Change". International Organization, 56 (4).

Keck, Margaret E dan Kathryn Sikkink, 1999. "Transnational AdvocacyNetworks in International and Regional Politics", International Social Science Journal, 159 (1).

Misran, Misran, 2012. "Pelaksanaan Syariat Islam di Aceh", Legitimasi: Jurnal Hukum Pidana dan Politik Hukum, 1 (2).

Nelaeva, Galina, 2010. "The Impact of Transnational Advocacy Networks on the Prosecution of Wartime Rape and Sexual Violence: The Case of the ICTR", International Social Science Review, 85 (1/2).

Noakes, Stephen, 2012. “Transnational Advocacy Networks and Moral Commitment: The Free Tibet Campaign Meets the Chinese State”, International Journal, 67 (2).

Pisani, Elizabeth dan Michael Butler, 2016. "Why do Indonesian Politicians Promote Sharia Laws? An Analytic Framework for Muslim-majority Democracies", Third World Quarterly, 38 (3).

Ridwansyah, Muhammad, 2016. "Mewujudkan Keadilan, Kepastian dan Kemanfaatan Hukum dalam Qanun Bendera dan Lambang Aceh", Jurnal Konstitusi, 13 (2).

Sperling, Valerie, Myra Marx Ferree, dan Barbara Risman, 2001. "Constructing Global Feminism: Transnational Advocacy Networks and Russian Women’s Activism”, Signs, 26 (4).

Ulya, Zaki, 2016. "Dinamika Penerapan Hukum Jinayat Sebagai 
Wujud Rekonstruksi Syariat Islam di Aceh”. Jurnal Rechts Vinding, 5 (1).

\section{Laporan Penelitian}

Amnesty International, 2014. Amnesty International Report 2013: The State of the World's Human Rights. London: Amnesty International Ltd.

, 2015. Amnesty International Report 2014:

The State of the World's Human Rights. London: Amnesty International Ltd.

2015. "Cruel, Inhuman, or Degrading Punishment”. Amnesty International Report 2014: The State of the World's Human Rights. London: Amnesty International Ltd.

\section{Publikasi Daring}

Al Jazeera News, 2017. "Mahmoud Hussein: Freedom of Expression is Valuable" [online]. Tersedia dalam http://www.aljazeera. com/news/2017/01/mahmoud-hussein-freedom-expressionvaluable-170116094941685.html [diakses 4 September 2017]

Amnesty International Australia, 2016. "Branding and Logo for Activists" [online]. Tersedia dalam https://www.amnesty.org. au/branding-logos-for-activists. [diakses 20 Mei 2018]

Amnesty International Canada, 2017. "Good News - Mahmoud Hussein Has Been Released in Egypt” [online]. Tersedia dalam http://www.amnesty.ca/our-work/good-news/good-news\%E2\%80\%93-mahmoud-hussein-has-been-released-egypt. [diakses 4 September 2017]

Board of Regents of the University of Wisconsin System, 2017. "International Relations", Department of Political Science, University of Wisconsin-Medison [online]. https://www. polisci.wisc.edu/fields/ir. [diakses 7 April 2017]

Direktorat Jenderal Kependudukan dan Pencatatan Sipil, 2015. "Jumlah Penduduk Aceh Berdasarkan Agama Semester I Tahun 2015” [online]. Tersedia dalam https://ppid.acehprov. 
go.id/v2/pages/opendata. [diakses 11 September 2017]

Doe, Richard, 2017. "The European Parliament Insists on a Cyanide Ban in Mining". London Mining Network [online]. https:// londonminingnetwork.org/news/the-european-parliamentinsists-on-a-cyanide-ban-in-mining/. [diakses 10 September 2017]

Human Rights Watch, 2018. "About". Human Rights Watch [online]. Tersedia dalam https://www.hrw.org/about.[diakses 5 Februari 2018]

Linggasari, Yohannie, 2015. "Kepala Dinas Syariat Islam Aceh: Qanun Jinayat Sesuai UU”. CNN Indonesia [online]. https://www.cnnindonesia.com/nasional/20151027214216 -12-87782/kepala-dinas-syariat-islam-aceh-qanun-jinayatsesuai-uu. [diakses 5 September 2017]

Serikat Perempuan, 2018. "Ruang Komunitas" [online]. Tersedia dalam http://www.solidaritasperempuan.org/category/ ruang-komunitas/. [diakses 20 Mei 2018]

The Wahid Institute, 2009. "Qanun Aceh Tahun 2009 tentang Hukum Jinayat". Documents [online]. Tersedia dalam http:// wahidinstitute.org/v1/Documents/Detail/?id=142/hl=id/ Qanun_Aceh_Tahun_2009_Tentang_Hukum_Jinayat [diakses 6 Februari 2018]

\section{Instrumen Legal}

Pemerintah Daerah Provinsi Nanggroe Aceh Darussalam, 2003a. "Qanun Provinsi Nanggroe Aceh Darussalam Nomor 12 Tahun 2003 tentang Minuman Khamar dan Sejenisnya", Lembaran Daerah Provinsi Nanggroe Aceh Darussalam Tahun 2003 Nomor 25 Seri D Nomor 12. Banda Aceh: Pemerintah Daerah Nanggroe Aceh Darussalam.

, 2003b. "Qanun Provinsi Nanggroe Aceh Darussalam Nomor 13 Tahun 2003 tentang Maisir (Perjudian)", Lembaran Daerah Provinsi Nanggroe Aceh Darussalam Tahun 2003 Nomor 26 Seri D Nomor 13. Banda Aceh: Pemerintah Daerah Nanggroe Aceh Darussalam. . (2003c). "Qanun Provinsi Nanggroe Aceh Darussalam Nomor 14 Tahun 2003 tentang Khalwat (Mesum)", 
Lembaran Daerah Provinsi Nanggroe Aceh Darussalam Tahun 2003 Nomor 27 Seri D Nomor 14. Banda Aceh: Pemerintah Daerah Nanggroe Aceh Darussalam.

(2014). "Qanun Provinsi Nanggroe Aceh Darussalam Nomor 6 Tahun 2014 tentang Hukum Jinayat", Lembaran Daerah Provinsi Nanggroe Aceh Darussalam Tahun 2014 Nomor 7. Banda Aceh: Pemerintah Daerah Nanggroe Aceh Darussalam.

Undang-Undang Republik Indonesia Nomor 11 Tahun 2006 tentang Pemerintahan Aceh, Lembaran Negara Republik Indonesia Tahun 2006 Nomor 62.

Undang-Undang Republik Indonesia Nomor 18 Tahun 2001 tentang Otonomi Khusus bagi Provinsi Daerah Istimewa Aceh sebagai Provinsi Nanggroe Aceh Darussalam, Lembaran Negara Republik Indonesia Tahun 1999 Nomor 172. 
Kegagalan Strategi Transnational Advocacy Network dalam

Menentang Pengesahan Qanun Jinayat di Aceh 